\title{
Calli Essential Oils Synergize with Lawsone against Multidrug Resistant Pathogens
}

\author{
Sameh S. M. Soliman $1,2, *$, Abrar I. Alsaadi ${ }^{3}$, Eman G. Youssef ${ }^{3,4}{ }^{,}$Gregory Khitrov ${ }^{5}$, \\ Ayman M. Noreddin 1,6, Mohamed I. Husseiny 2,7 (D) and Ashraf S. Ibrahim 3,8,* \\ 1 Sharjah Institute for Medical Research, and College of Pharmacy, University of Sharjah, \\ P.O. Box 27272, Sharjah, UAE; anoreddin@sharjah.ac.ae \\ 2 Faculty of Pharmacy, Zagazig University, Zagazig 44519, Egypt; melsayed@coh.org \\ 3 Division of Infectious Diseases, Los Angeles Biomedical Research Institute, Harbor-UCLA Medical Center, \\ Torrance, CA 90509, USA; aalsaadi1@toromail.csudh.edu (A.I.A.); emangouda@psas.bsu.edu.eg (E.G.Y.) \\ 4 Department of Biotechnology \& Life Sciences, Faculty of Postgraduate Studies for Advanced \\ Sciences (PSAS), Beni-Suef University, Beni-Suef, Egypt \\ 5 Molecular Instrumentation Center, Department of Chemistry, University of California Los Angeles, Los \\ Angeles, CA 90095, USA; khitrov@chem.ucla.edu \\ 6 East Virginia Medical School Family Practice, Norfolk, VA 23507, USA \\ 7 Department of Translational Research \& Cellular Therapeutics, Beckman Research Institute of City of Hope, \\ Duarte, CA 91010-3000, USA \\ 8 David Geffen School of Medicine at UCLA, Los Angeles, CA 90095, USA \\ * Correspondence: ssoliman@sharjah.ac.ae (S.S.M.S.); ibrahim@labiomed.org (A.S.I.); Tel.: +971-6505-7472
}

Received: 30 October 2017; Accepted: 12 December 2017; Published: 20 December 2017

\begin{abstract}
The fast development of multi-drug resistant (MDR) organisms increasingly threatens global health and well-being. Plant natural products have been known for centuries as alternative medicines that can possess pharmacological characteristics, including antimicrobial activities. The antimicrobial activities of essential oil (Calli oil) extracted from the Calligonum comosum plant by hydro-steam distillation was tested either alone or when combined with lawsone, a henna plant naphthoquinone, against MDR microbes. Lawsone showed significant antimicrobial activities against MDR pathogens in the range of 200-300 $\mu \mathrm{g} / \mathrm{mL}$. Furthermore, Calli oil showed significant antimicrobial activities against MDR bacteria in the range of 180-200 $\mu \mathrm{g} / \mathrm{mL}$, Candida at $220-240 \mu \mathrm{g} / \mathrm{mL}$ and spore-forming Rhizopus fungus at $250 \mu \mathrm{g} / \mathrm{mL}$. Calli oil's inhibition effect on Rhizopus, the major cause of the lethal infection mucormycosis, stands for $72 \mathrm{~h}$, followed by an extended irreversible white sporulation effect. The combination of Calli oil with lawsone enhanced the antimicrobial activities of each individual alone by at least three-fold, while incorporation of both natural products in a liposome reduced their toxicity by four- to eight-fold, while maintaining the augmented efficacy of the combination treatment. We map the antimicrobial activity of Calli oil to its major component, a benzaldehyde derivative. The findings from this study demonstrate that formulations containing essential oils have the potential in the future to overcome antimicrobial resistance.
\end{abstract}

Keywords: antimicrobials; Calligonum; essential oil; lawsone; combination treatment; liposomes

\section{Introduction}

The emergence of MDR microbial strains with the lack of development of new antimicrobials endangers the future management of infectious diseases. Thus, alternatives to traditionally-used antibiotics can be of great benefit in combating MDR pathogens. Compounds isolated from natural sources are alternatives to many drugs, including those with antimicrobial activity, mainly because of their reduced side effects compared to synthetic drugs [1]. Natural compounds can be considered 
as privileged structures functionally evolved for the purpose of interaction with specific targets. Many attempts have been made to investigate the potential role of plant extracts and their major active compounds to overcome antibiotic resistance. For example, naphthoquinones, including lawsone (2-hydroxy-1,4-naphthoquinone), are promising antibacterial and antifungal compounds [2-4]. Lawsone is the principal active ingredient of the Henna plant $[5,6]$. Although lawsone is known as an antimicrobial compound, it's effect is not consistent when tested against different microbes including Candida and spore-forming fungi [7]. Furthermore, lawsone is not stable and shows a degradation behavior over time [8].

Essential oils are also products of the secondary metabolism of aromatic plants. Essential oils are known to possess different biological properties including antimicrobial activities [9]. Essential oils are multi-component products and, hence, can exert greater antimicrobial activity compared to their major components alone [9]. Due to the multi-component nature of essential oils, antimicrobial drug resistance is less likely to be developed since these oils affect numerous targets in the pathogen [10]. Consistent with this hypothesis, clinical resistance to essential oil has not yet been reported [11]. Essential oils exert their antimicrobial effect mainly by affecting membrane permeability [12] due to their lipophilic nature [13].

Calligonum comosum is an aromatic plant reported as a source of essential oil [14]. Although the plant extract shows antimicrobial activities [15-17], its antimicrobial properties have never been attributed to its oil content. Furthermore, the broad spectrum antimicrobial activities and the active components of the oil extracted from United Arab Emirates (UAE) Calligonum plant have never been investigated.

In this study, we investigated the antimicrobial activities of lawsone from Henna and Calli oil from Calligonum comosum, alone or in combination, against several pathogens known for their resistance to antibiotics. We also investigated the toxicity of these plant extracts with or without liposome preparations. We report on the broad-spectrum activity of both lawsone and Calli oil against methicillin-resistant Staphylococcus aureus (MRSA), Gram-negative MDR bacteria, Candida species (including C. auris), and the spore-forming Rhizopus fungus, the major cause of the lethal infection mucormycosis. We also show the enhanced activity of combination of lawsone and Calli oil against these priority pathogens. Finally, liposome preparations of lawsone and Calli oil are less toxic to mammalian cells.

\section{Results}

\subsection{The Anti-Microbial Effect of Lawsone and Calli Oil}

\subsubsection{Lawsone is a Potential Antimicrobial Candidate}

The potential antimicrobial activity of lawsone was evaluated against several priority MDR pathogens. Lawsone showed strong cidal activity against Gram-positive MRSA and Gram-negative bacteria including MDR Pseudomonas aeruginosa, Klebsiella pneumoniae carbapenemase (KPC)-producing bacteria, extensively drug-resistant Acinetobacter baumannii, and E. coli (Figure 1A). Similarly, lawsone demonstrated cidal activity against Candida species including C. albicans (SC5314), C. krusei, C. glabrata, C. tropicalis, and the MDR C. auris (CAU09) (Figure 1B). The growth inhibition was concentration-dependent with a range of $100-200 \mu \mathrm{g} / \mathrm{mL}$ being sufficient to significantly inhibit the growth of all tested bacteria spp. Lawsone at $200 \mu \mathrm{g} / \mathrm{mL}$ caused $\sim 90 \%, 88 \%, 92 \%, 94 \%$ and $96 \%$ inhibition of E. coli, MRSA, KPC-producing bacteria, A. baumannii, and P. aeruginosa, respectively (Figure 1A) compared to a $100 \%$ inhibition due to $0.7-10 \mu \mathrm{g} / \mathrm{mL}$ colistin for Gram-negative bacteria and $3 \mu \mathrm{g} / \mathrm{mL}$ vancomycin for MRSA (Supplementary Table S1). On the other hand, $200 \mu \mathrm{g} / \mathrm{mL}$ lawsone resulted in $\sim 60 \%$ inhibition of the growth of all tested Candida spp. (Figure 1B) compared to a $100 \%$ inhibition due to $1-3 \mu \mathrm{g} / \mathrm{mL}$ ketoconazole (Supplementary Table S2). The effective MIC of lawsone for bacteria strains and Candida was 220-240 and 250-300 $\mu \mathrm{g} / \mathrm{mL}$, respectively (Supplementary Tables S1 and S2). 
(A)

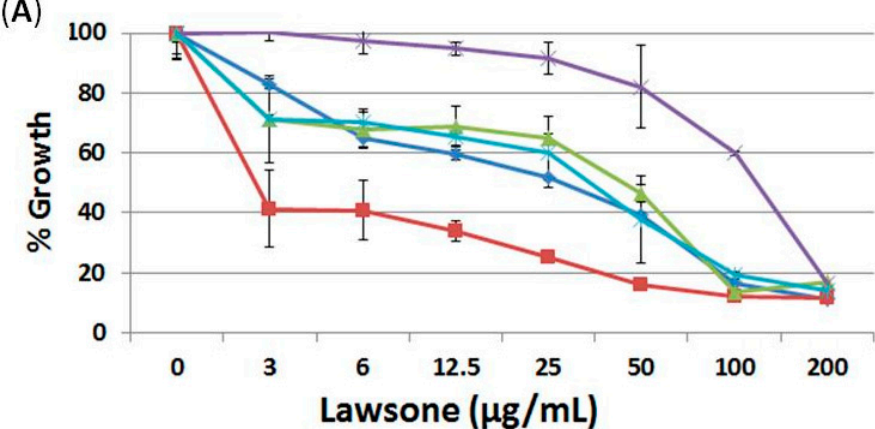

(B)

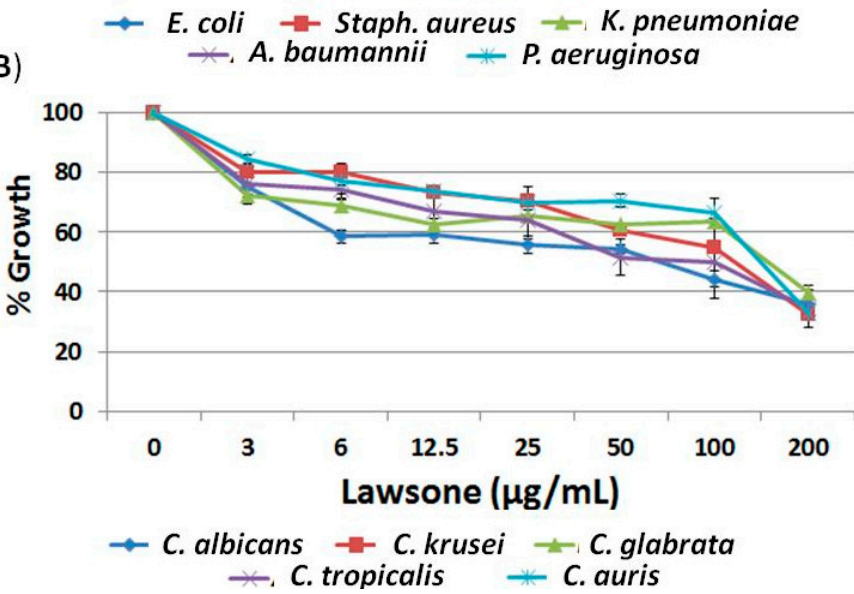

Figure 1. Antibacterial and anti-Candida effects of lawsone. The effect of different lawsone concentrations on (A) Gram-negative and Gram-positive bacteria, and (B) different Candida spp. Lawsone at $200 \mu \mathrm{g} / \mathrm{mL}$ caused significant inhibition of the growth of all tested bacterial spp. and Candida strains down to $>90 \%$ and $60 \%$, respectively. The data display the mean of the percentage of microbial growth at different concentrations \pm standard error of the mean.

\subsubsection{Calligonum Plant Essential Oil (Calli Oil) Showed Potential Antimicrobial Activities}

Calli oil isolated from Calligonum comusum (Arta) plant by hydro-steam distillation showed broad spectrum antimicrobial activities. At a concentration of $160 \mu \mathrm{g} / \mathrm{mL}$, the extracted oil demonstrated 66-71\% inhibition of all tested bacterial spp. compared to untreated controls (Figure 2A). Similarly, Calli oil inhibited the growth of all tested Candida spp. including C. albicans (SC5314), C. krusei, C. glabrata, C. tropicalis, and C. auris (CAU09) (Figure 2B). The inhibition was also concentration-dependent with $160 \mu \mathrm{g} / \mathrm{mL}$ significantly reducing the yeast growth by $\sim 60 \%$. The MIC of Calli oil was determined as $180-200 \mu \mathrm{g} / \mathrm{mL}$ for the bacterial strains and $220-240 \mu \mathrm{g} / \mathrm{mL}$ for Candida spp. (Supplementary Tables S1 and S2).

The amount of Calli oil extracted from Calligonum plant was calculated as $0.4 \mu \mathrm{g}$ oil/gm plant (dry weight) and the major components were 4-(1-methylethyl)-benzaldehyde (cuminaldehyde, 50\%), 2-caren-10-al (11.3\%), and 1-(1,5-dimethyl-4-hexenyl-4-methyl-benzene (curcumene, 10\%) identified by GC-MS analysis (Figure 3). 


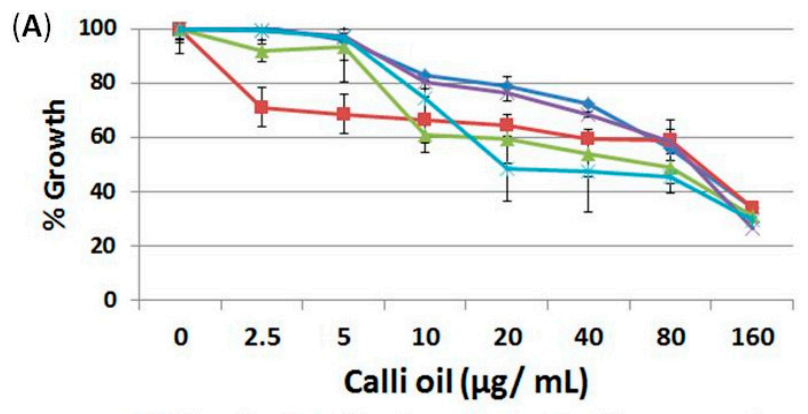

$\rightarrow$ E. coli $\rightarrow$ Staph. aureus $\rightarrow$ K. pneumoniae *A. baumannii - . aeruginosa

(B)

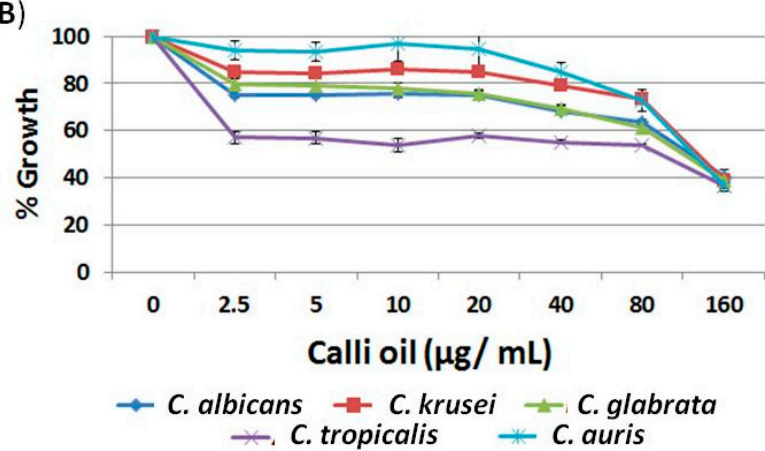

Figure 2. Antibacterial and anti-Candida effects of Calli oil isolated from Calligonum comosum grows in the UAE. The effect of different Calli oil concentrations on (A) Gram-negative and Gram-positive bacteria and (B) different Candida spp. Calli oil at $160 \mu \mathrm{g} / \mathrm{mL}$ caused significant inhibition of the growth of all tested bacterial spp. and Candida strains down to ca. $>60 \%$. The data display the mean of the percentage of microbial growth at different concentrations \pm standard error of the mean.

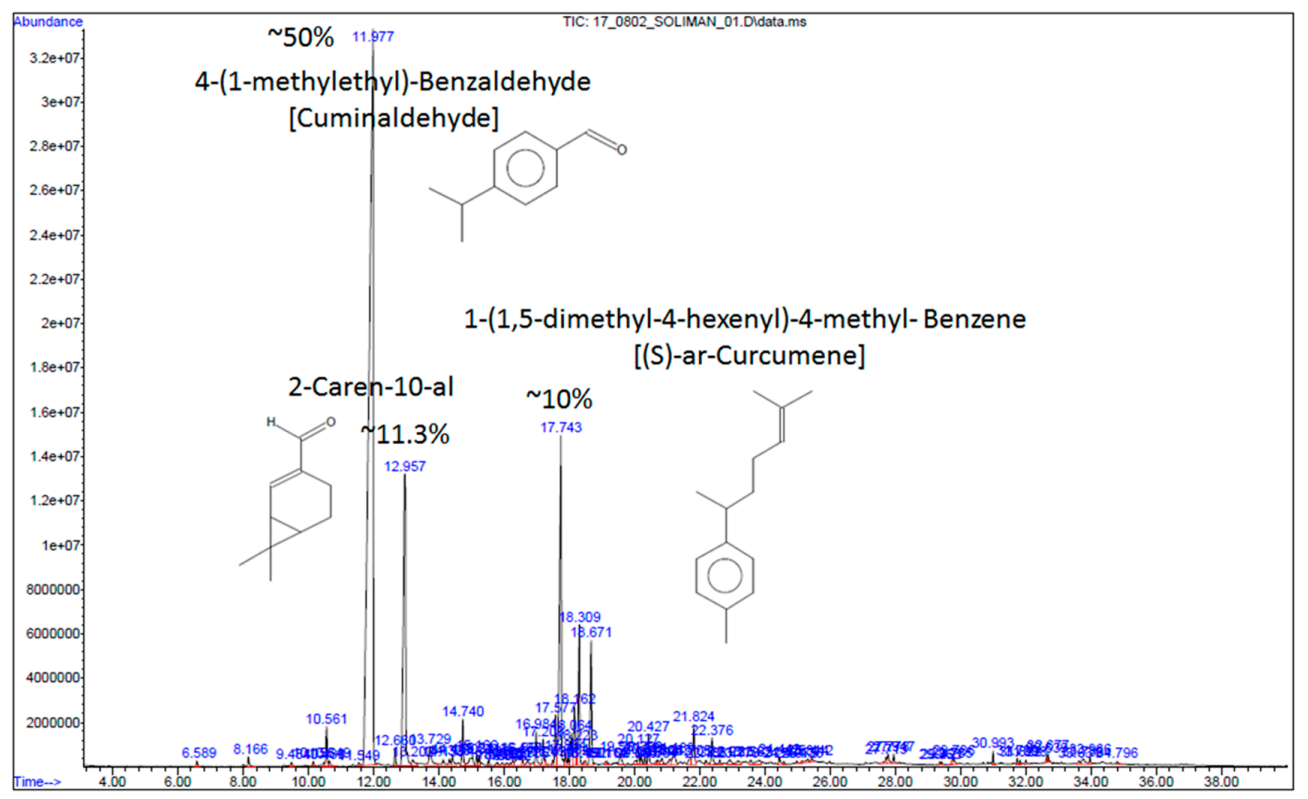

Figure 3. GC-MS analysis of Calli oil. The analysis showed that 4-(1-methylethyl)-benzaldehyde, 2-caren-10-al and 1-(1,5-dimethyl-4-hexenyl-4-methyl-benzene were the three major components of Calli oil. Y axis represents the abundance of the peaks. 


\subsection{The Synergistic Effect of both Lawsone and Calli Oil}

\subsubsection{Calli Oil Augmented the Antimicrobial Activities of Lawsone}

Preliminary study by mixing lawsone and Calli oil showed antimicrobial activities that exceeded the activity of each product alone. Briefly, a mixture of $50 \mu \mathrm{g} / \mathrm{mL}$ lawsone and $40 \mu \mathrm{g} / \mathrm{mL}$ Calli oil (for a total of $90 \mu \mathrm{g} / \mathrm{mL}$ ) caused $\geq 90 \%$ growth inhibition of all tested bacterial strains (Figure $4 \mathrm{~A}$ ). Similarly, a mixture of $75 \mu \mathrm{g} / \mathrm{mL}$ lawsone and $60 \mu \mathrm{g} / \mathrm{mL}$ Calli oil (for a total of $135 \mu \mathrm{g} / \mathrm{mL}$ ) caused $>90 \%$ growth inhibition of all tested Candida spp. (Figure 4B). The MIC of the combination preparation against the tested bacteria, or Candida ranged between $100-150 \mu \mathrm{g} / \mathrm{mL}, \mathrm{a} \sim 50 \%$ reduction in the MIC values of each product alone (Supplementary Tables S1 and S2).
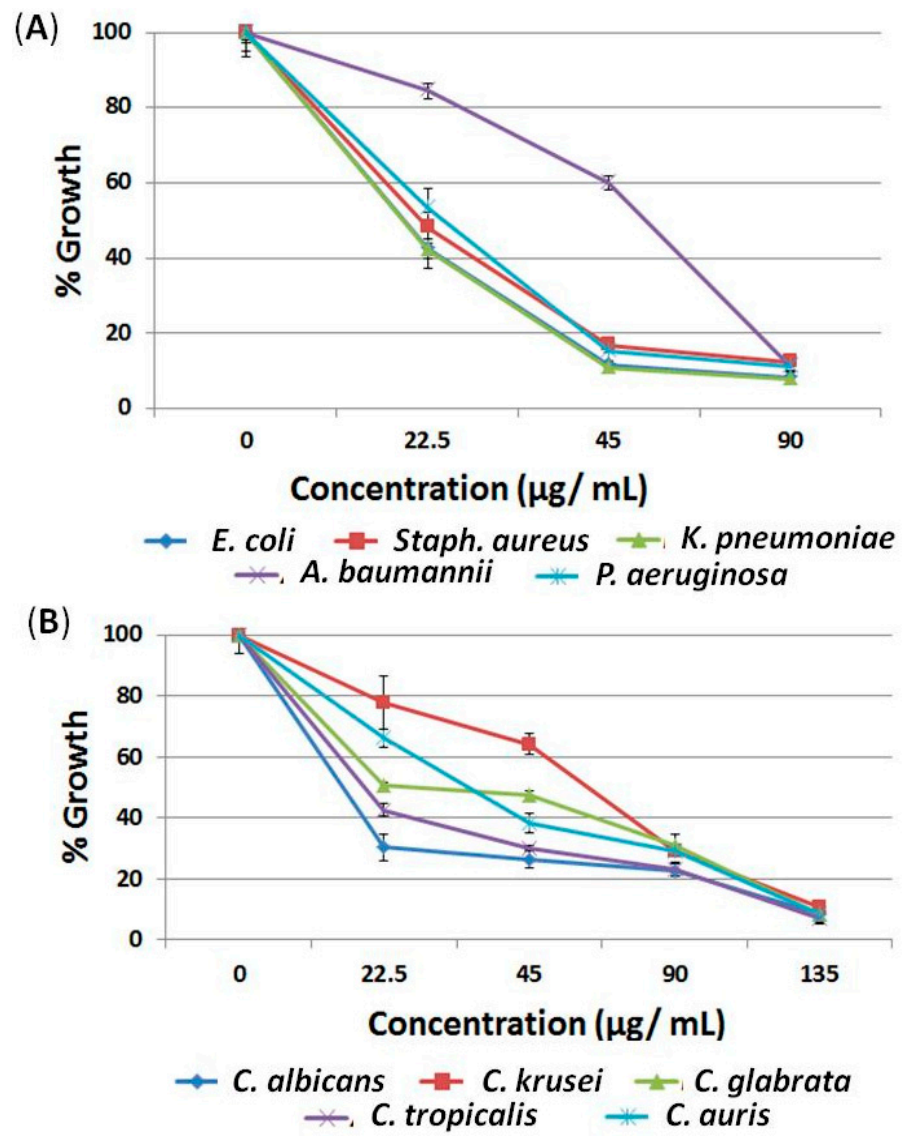

Figure 4. Antibacterial and anti-Candida effects of combined treatment using Calli oil and lawsone. The effects of different concentrations of combined substances on (A) Gram-negative and Gram-positive bacteria and (B) different Candida spp. Combination of lawsone and Calli oil showed a synergistic effect on MDR microbes with $90 \mu \mathrm{g} / \mathrm{mL}$ and $135 \mu \mathrm{g} / \mathrm{mL}$ caused more than $90 \%$ inhibition of tested bacterial spp. and Candida spp., respectively. The data display the mean of the percentage of microbial growth at different concentrations \pm standard error of the mean.

\subsubsection{Calli Oil Enhanced the Antifungal Activities of Lawsone against Rhizopus Fungus}

Due to the enhanced efficacy of combination of Calli oil and lawsone against MDR bacteria and Candida, the combined preparation was tested against spore-forming fungus, Rhizopus delemar. R. delemar PDA cultures were treated with either lawsone, or Calli oil, at concentrations 100, 200, and $250 \mu \mathrm{g} / \mathrm{mL}$. Similarly, R. delemar cultures were treated with combined Calli oil/lawsone at concentrations 50, 100 and $150 \mu \mathrm{g} / \mathrm{mL}$. All cultures were incubated for $48 \mathrm{~h}$ in the dark at $37^{\circ} \mathrm{C}$ followed by measuring inhibition zone of growth using disc diffusion assay. Lawsone, Calli oil, and 
their combined preparation caused significant inhibition zone of growth corresponding to $\sim 18 \pm 0.75$, $23 \pm 0.5$, and $20 \pm 0.43 \mathrm{~mm}$ in diameter, respectively (Figure 5). The antimicrobial effects of tested substances on Rhizopus fungus was extended for more than seven days, where the oil alone caused the appearance of white spores at the zone of inhibition, lawsone showed less sporulated thinner hyphae and the combined treatment caused less number of white spores, but thinner hyphae (Figure 5).

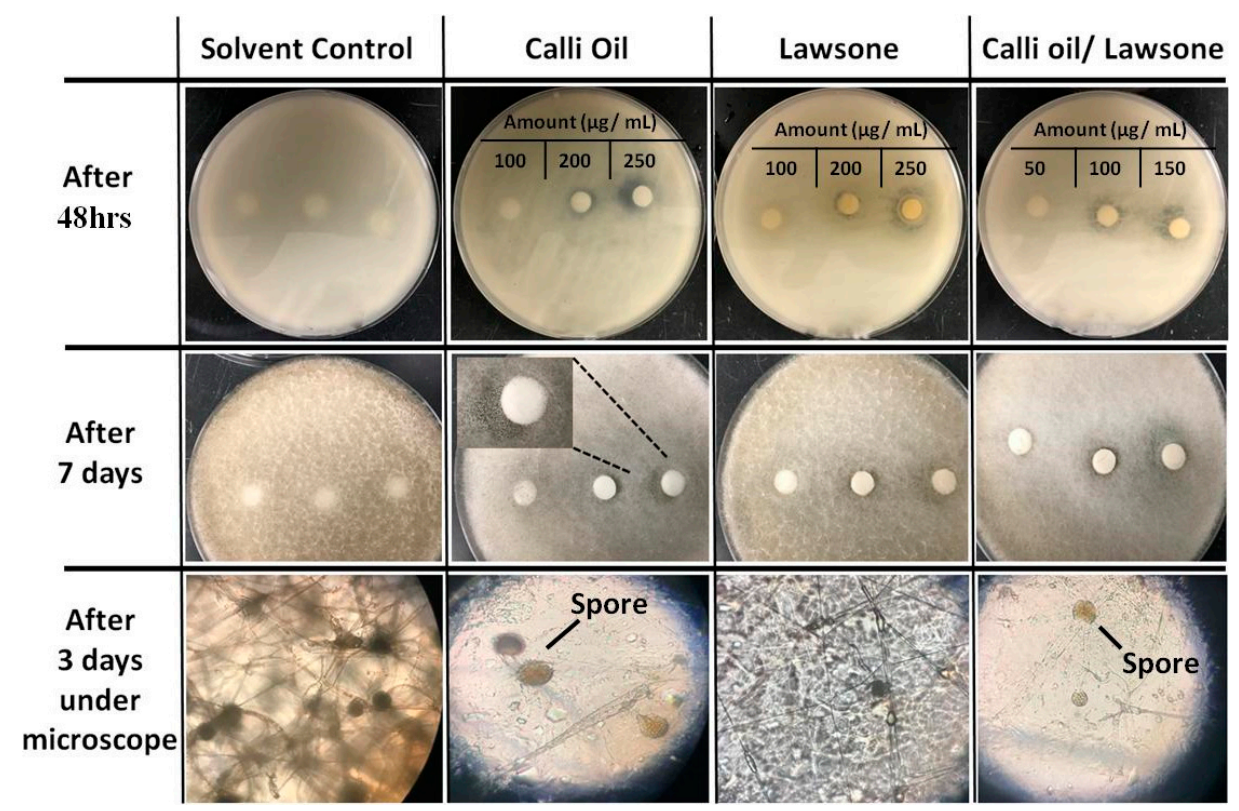

Figure 5. The antifungal effect of lawsone, Calli oil and combined Calli oil/lawsone on $R$. delemar, a spore-forming fungus at different concentrations. The effect was measured visually by disc diffusion assay and under light microscope. The experiment was repeated at least three times.

\subsection{The Effect of Liposome Preparation on the Antimicrobial Activity of Lawsone and Calli Oil}

Liposome preparation enhanced activities, reduced the toxicity of both natural products, and promoted the stability of lawsone.

\subsubsection{Liposome Preparation Enhanced the Antimicrobial Activity of Natural Product Employed}

Liposomes made of lawsone and Calli oil by the ether injection method caused significant growth inhibition to bacteria and Candida similar to their combination treatment (Supplementary Tables S1 and S2). Measuring the amount of liposome-incorporated Calli oil (by GC-MS) and lawsone (by LC-MS) indicated that $\sim 87 \%$ of the combined oil was included (calculated by measuring the cuminaldehyde content of the oil) and only $\sim 76 \%$ of lawsone was incorporated in the final liposomes preparation. These results indicate that Calli oil combined with lawsone with or without liposome preparation enhanced the antimicrobial activities over each natural product alone by ca. three-fold versus bacteria and ca. four-fold versus Candida. On the other hand, liposome preparation showed similar antimicrobial pattern measured by disc diffusion assay up to one month of storage at room temperature; compared to reduction in antimicrobial activity of lawsone alone with time (data not shown). The results indicated that liposomes preparation promoted the stability of lawsone.

\subsubsection{Liposome Preparation Enhanced the Anti-Rhizopus Activity of Natural Product Employed}

Liposomes preparation of Calli oil/lawsone showed significant growth inhibition (zone of inhibition, $30 \mathrm{~mm}$ diameter) compared to combination treatment (20 mm diameter) (Figure 6A). Liposome preparation caused a significant $(p=0.0001)$ reduction in the fungal growth greater than, or equal to, two-fold compared to each substance alone measured by microdilution assay (Figure 6B). 
The inhibitory concentrations of lawsone, Calli oil, combined treatment and liposome against $R$. delemar were $250 \mu \mathrm{g} / \mathrm{mL}, 250 \mu \mathrm{g} / \mathrm{mL}, 150 \mu \mathrm{g} / \mathrm{mL}$ (i.e., $80 \mu \mathrm{g} / \mathrm{mL}$ lawsone and $70 \mu \mathrm{g} / \mathrm{mL}$ Calli oil) and $\sim 150 \mu \mathrm{g} / \mathrm{mL}$ compared to $5 \mu \mathrm{g} / \mathrm{mL}$ amphotericin B as the positive control.
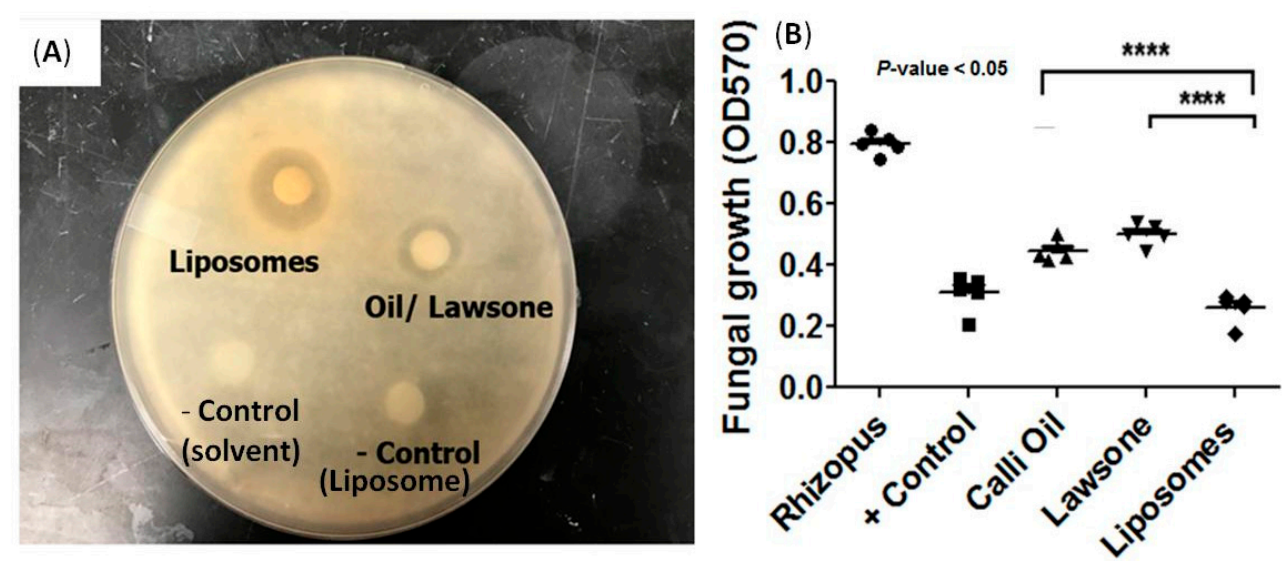

Figure 6. The antifungal effect of liposomes compared to the combined treatment and individual Calli oil or lawsone on $R$. demelar fungus. Comparison between liposomes prepared by mixing equal amounts of Calli oil and lawsone and combined amount of both substances on Rhizopus fungus using (A) disc diffusion assay and (B) microdilution assay. The data display the mean of the growth of Rhizopus \pm standard error of the mean. The statistical significance was calculated with one-way ANOVA and significance level indicated by asterisks $(* * * * 0.0001)$.

\subsubsection{Liposome Preparation Significantly Reduced the Toxicity of the Natural Product Employed}

The cytotoxic effect of lawsone, Calli oil, or their combination, was compared using both hemolysis of red blood cells (RBCs) and mammalian cell injury assays. Liposome preparation of lawsone and Calli oil was significantly ( $p=0.0001$ ) less toxic when compared to each natural product alone (ca. sevenand four-fold reduction in hemolytic toxicity versus lawsone or Calli oil, respectively) (Figure 7A). Furthermore, liposome caused significant $(p=0.0001$ and $p=0005)$ reduction in damage to human umbilical vein endothelial cells (HUVECs) ( 2.5-fold reduction in damage when compared to each product alone) (Figure 7B).
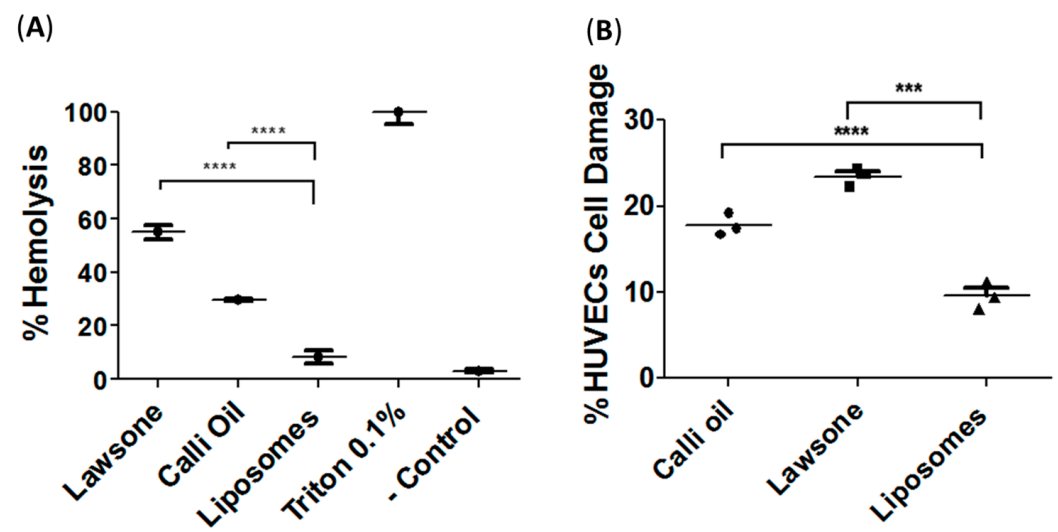

Figure 7. Cytotoxicity assays of prepared liposomes compared to Calli oil or lawsone alone using either (A) RBCs hemolysis assay or (B) HUVEC injury assay. The data display the mean of the percentage of hemolysis or percentage of cell damage \pm standard error of the mean. The statistical significance was calculated with one-way ANOVA and significance level indicated by asterisks $\left({ }^{* *} p=0.0005\right.$, and $* * * * p=0.0001)$. 


\section{Discussion}

Lawsone showed potential antimicrobial activities against Gram-positive and Gram-negative bacteria, Candida and spore-forming fungi within the range of 200-300 $\mu \mathrm{g} / \mathrm{mL}$. The antimicrobial activity of lawsone is partially lower than the results obtained by Rahmoun, et al., 2012 [4]. The minimum amount required for inhibition is different than what has been reported possibly because of the degradation behaviors of lawsone [8].

Consistent with previous reports [14], we found that Calligonum comosum collected from the UAE desert is a good source of essential oils. Although the plant extract is known to have antimicrobial activity [15], to our knowledge this study is the first to attribute this antimicrobial activity to Calligonum oil (Calli oil) against MDR pathogens including Gram-positive and Gram-negative bacteria, Candida species, and the Mucorales mold, R. delemar. Another different finding from our studies than previously reported studies lies in the composition of oils extracted from UAE Calligonum comosum. The major components of the oil isolated in our study were 4-(1-methylethyl)-benzaldehyde (cuminaldehyde), 2-caren-10-al and 1-(1,5-dimethyl-4-hexenyl-4-methyl-benzene (curcumene), whereas in a previous study essential oil from the same plant was reported as lauric, myristic, and palmitic acids [14]. This difference could be due to the geographical differences from where the plants were obtained [18]. It is prudent to mention that the potential antimicrobial activities of benzaldehyde and cuminaldehyde were previously realized $[19,20]$.

One critical finding of our studies is the activity seen with Calli oil against the Mucorales mold, R. delemar, a rare, but lethal, fungal infection. It appears in addition to the direct effect of the Calli oil on the growth of the spore-forming mold, it appears the oil caused discoloration of the black spores potentially due to prevention of melanin formation [21]. Melanin's role in virulence of fungal pathogens, including the ability to resist phagocyte killing is well-described [21]. Thus, Calli oil has the potential to directly kill this lethal mold and also enhance the immune system to clear the infection.

Synergistic combination between conventional antibiotics and essential oils is currently under investigation and can represent a potential area for future novel treatment regimens in combating antimicrobial resistance [22]. Such combination treatment has the potential to surpass monotherapy by producing enhanced antimicrobial activity [23]. Our studies of combining lawsone and Calli oil clearly support this concept and represent a future promising novel treatment for MDR pathogens.

Liposomes are spherical vesicles consisting of outer lipid bilayers surrounding aqueous core [24]. Hydrophilic antibiotics can be encapsulated in the internal aqueous compartment, whereas hydrophobic drugs may bind to or incorporate in the lipid bilayer [25]. Liposome encapsulation of antibiotics can increase the therapeutic index of antibiotics by augmenting their concentrations at the site of infection and reducing their toxicity [26]. Similarly, we found that the activity of liposomes prepared from lawsone and Calli oil was enhanced and at lower doses. We also found that these liposome preparations were less toxic than the natural products and provided stability over a long period of time. We hypothesize that the liposome preparation of using essential oil within the lipid layer likely potentiates the antimicrobial activities since both the hydrophobic outer layer and the inner aqueous core have antimicrobial activities. A multi-component outer oily layer will disturb the microbial membrane and, hence, enhances and stabilizes the effect of aqueous core-containing lawsone. This approach is also likely to improve treatment of severe infections since liposomes can achieve a significant longer blood and tissue half-life [27]. Consistent with Sherry, et al. [28], the entrapped oil was greater than the entrapped aqueous substance mainly because the oil entrapped with the lipid layer and, hence, stabilized its presence; however, lawsone in the aqueous core may be leaked from the prepared liposomes.

As concluding remarks, the formulation of antimicrobial liposomes by combining both hydrophilic natural products and hydrophobic essential oil can be a future promising area for improved delivery of naturally present products with antimicrobials activity against MDR-resistant pathogens. The multi-functional entrapped essential oil in these liposomes can stabilize the structure, increase the interaction of the liposome with the hydrophobic surface of pathogens, and directly affect the 
viability of the targeted microbes. Additionally, and as noted before [29] these liposomes can reduce any potential toxicity of the delivered drugs and increase their half-life in plasma and targeted tissues.

\section{Materials and Methods}

\subsection{Materials}

Lawsone, colistin, vancomycin, ketoconazole, and amphotericin B were all purchased from Sigma (Sharjah, UAE).

\subsection{Essential Oil Extraction}

The air-dried Calligonum comosum aerial parts were collected from the desert of Sharjah, UAE. The plant was ground to obtain a homogeneous powder and subjected to hydro-steam distillation [30] for $3 \mathrm{~h}$. Collected oil was dried over anhydrous sodium sulphate and then stored at $4{ }^{\circ} \mathrm{C}$ in sealed vials before antimicrobial testing and GC-MS analysis.

\subsection{Studying the Antimicrobial Activities of Tested Substances}

The antibacterial activity of lawsone and Calli oil was studied against methicillin-resistant Staphylococcus aureus (MRSA) strain and Gram-negative bacteria including P. aeruginosa, E. coli, and the multidrug resistant (MDR) A. baumannii and Klebsiella pneumoniae on agar plates and in liquid broth media according to a modified version of Clinical and Laboratory Standards Institute (CLSI) [31]. Briefly, $0.1 \mathrm{~mL}$ containing $10^{5} \mathrm{CFU} / \mathrm{mL}$ was spread on Luria-Bertani (LB) agar plates [32]. The plates were then incubated at $37^{\circ} \mathrm{C}$ with filter discs $(8 \mathrm{~mm}$ diameter) saturated with different dilutions of lawsone $(3,6,12,25,50,100$ and $200 \mu \mathrm{g} / \mathrm{mL})$, Calli oil $(2.5,5,10,20,40,80$ and $160 \mu \mathrm{g} / \mathrm{mL})$ and their combination $(12.5,25,50$ and $75 \mu \mathrm{g} / \mathrm{mL})$ for $24 \mathrm{~h}$. For the microdilution method, the microbial strains were incubated with the aforementioned concentrations of substances into LB broth media inoculated with $10^{5} \mathrm{CFU} / \mathrm{mL}$ in 96 -well microplates at $37^{\circ} \mathrm{C}$ for $24 \mathrm{~h}$ and the microbial growth (turbidity) was measured by microplate reader (DYNEX Technologies, Chantilly, VA, USA) at $\mathrm{OD}_{600}$. Each test was performed in triplicate. The anti-Candida activities were similarly measured against C. albicans (SC5314), C. krusei, C. glabrata, C. tropicalis, and C. auris (CAU09) and according to a modified version of Clinical and Laboratory Standards Institute (CLSI) (Wayne, PA, USA) [31] using LB agar plates for disc diffusion assay or yeast nitrogen base (YNB) supplemented with $100 \mathrm{mM}$ glucose for microdilution assay.

For the spore-forming fungus (Rhizopus delemar), the antimicrobial activities were determined by using the reference procedure of the Antifungal Susceptibility Testing Subcommittee of EUCAST for spore-forming molds [33]. Briefly, flat-bottom microdilution 96 well-plates were loaded with $200 \mu \mathrm{L}$ RPMI 1640 medium supplemented with $2 \%$ glucose and an inoculum of $2 \times 10^{5} \mathrm{CFU} / \mathrm{mL}$. Growth inhibition was visually determined at 24,48 and $72 \mathrm{~h}$. The reading was performed after 5 min of agitation on a microdilution plate shaker with a spectrophotometer (DYNEX Technologies, Chantilly, VA, USA) at $570 \mathrm{~nm}$.

Colistin, vancomycin, ketoconazole, and amphotericin B were used as positive controls against Gram negative bacteria, Gram-positive bacteria, Candida and fungi, respectively. Cultures without antimicrobials served as negative controls. All experiments were repeated in triplicate. All microbial strains are clinical isolates from patients who were seen at Harbor-UCLA Medical Center, Torrance, CA, USA. The antimicrobial activities of all substances were tested either by disc diffusion assay, microdilution assay or by measuring the minimum inhibitory concentration (MIC).

\subsection{Stability Testing}

Calli oil, lawsone, and their liposome preparation were stored separately at room temperature $\left(\sim 25^{\circ} \mathrm{C}\right)$ for one month. The antimicrobial activity of each substance alone and in liposome preparation 
was measured by disc diffusion assay at different time intervals. The results obtained were compared to those obtained prior to storage. The diameter of zone of growth inhibition (in mm) was read at $24 \mathrm{~h}$.

\subsection{Cytotoxicity Assay}

The cytotoxic assays of tested substances were performed by hemolysis assay and mammalian cell damage assay as reported below.

\subsubsection{Hemolysis Assay}

Each tested substance was measured as the amount of hemoglobin released by the lysis of human erythrocytes $[34,35]$. Briefly, fresh whole blood from healthy individual was collected into heparinized vacutainer from Harbor-UCLA Hospital and $1 \mathrm{~mL}$ whole blood was immediately centrifuged at $500 \times g$ for 10 min using a benchtop centrifuge (Eppendorf 5804R refrigerated benchtop, Pittsburgh, PA, USA). The erythrocytes were washed three times with DPBS supplemented with $1 \mathrm{mg} / \mathrm{mL}$ bovine serum albumin (BSA) and then re-suspended to $3 \times 10^{7}$ cells $/ \mathrm{mL}$ in DPBS. Washed cells $\left(3 \times 10^{6}\right.$ cells per well) were incubated with the substance dissolved in the washing buffer at different concentrations (ranging from 100 to $200 \mu \mathrm{g} / \mathrm{mL}$ ) in round-bottomed 96-well plates in a final volume of $200 \mu \mathrm{L}$. Washing buffer and $0.1-1 \%$ Triton X-100 were used as negative and positive controls, respectively. The plate was incubated at $37^{\circ} \mathrm{C}$ for $30 \mathrm{~min}$, followed by $30 \mathrm{~min}$ incubation on ice, and the intact cells were precipitated by centrifugation at $500 \times g$ for $10 \mathrm{~min}$ at $4{ }^{\circ} \mathrm{C}$ and the supernatants $(125 \mu \mathrm{L})$ were transferred to a flat-bottom 96-well plate to measure hemoglobin release by absorbance at $405 \mathrm{~nm}$ using a microplate reader. The absorbance values for each sample were subtracted from the absorbance value obtained for washing buffer-treated cells and the hemolytic activity (\%) was calculated. The experiment was conducted in triplicate and the data was analyzed using two-way analysis of variance (ANOVA). The $50 \%$ cytotoxic concentration $\left(\mathrm{CC}_{50}\right)$ values were calculated as the concentration of substance caused $50 \%$ hemolysis compared to $100 \%$ hemolysis of erythrocytes treated with $0.1 \%$ triton X-100. Written informed consent was obtained from donor for the use of his/her blood. All experimental procedures were approved by Institutional Review Board (IRB) of LA Biomed under protocol 11671-11.

\subsubsection{Mammalian Cell Damage Assay}

Human umbilical vein endothelial cells (HUVEC) damage were quantified using a ${ }^{51} \mathrm{Cr}$ release assay [36]. Briefly, cells grown in 96-well tissue culture plates containing detachable wells were incubated with $1 \mu \mathrm{Ci}$ / well $\mathrm{Na}_{2}{ }^{51} \mathrm{CrO}_{4}(\mathrm{ICN})$ in $\mathrm{M}-199$ medium for $16 \mathrm{~h}$. On the day of the experiment, the unincorporated ${ }^{51} \mathrm{Cr}$ was aspirated, and wells were washed twice with pre-warmed HBSS. Cells were treated with substances suspended in RPMI 1640 medium supplemented with glutamine and incubated at $37{ }^{\circ} \mathrm{C}$ in a $5 \% \mathrm{CO}_{2}$ incubator. Spontaneous ${ }^{51} \mathrm{Cr}$ release was determined by incubating the cells only in culture medium supplemented with glutamine. After $16 \mathrm{~h}$ incubation, the medium was aspirated from each well and transferred to glass tubes, and cells were manually detached and placed into another set of tubes. The amount of ${ }^{51} \mathrm{Cr}$ in the aspirate and the detached well was determined by gamma counting. The total amount of ${ }^{51} \mathrm{Cr}$ incorporated by the cells in each well was calculated as the sum of radioactive counts per min of the aspirated medium and radioactive counts of the corresponding detached wells. After data were corrected for variations in the amount of tracer incorporated in each well, the percentage of specific cell release of ${ }^{51} \mathrm{Cr}$ was calculated as follows: $(($ experimental release $)-($ spontaneous release $)) /(1-($ spontaneous release $))$. Each experimental condition was tested in triplicate, and the experiment was repeated twice.

\subsection{Gas Chromatography-Mass Spectrometry (GC-MS)}

GC-MS measurements were carried out using an Agilent model 7683 (Wilmington, DE, USA) autosampler, 6890 gas chromatograph, and 5975 inert mass selective detector in the electron impact (EI) mode. EI energy was set to $70 \mathrm{eV}$. Separation was carried out on an Agilent HP5-MS column with dimensions $30 \mathrm{~m} \times 250 \mu \mathrm{m} \times 0.25 \mu \mathrm{m}$. Ultra-high purity grade He (Airgas, Kennesaw, GA, 
USA) was used as carrier gas with the flow set to $0.8 \mathrm{~mL} / \mathrm{min}$ in constant flow mode. The initial oven temperature was set to $45^{\circ} \mathrm{C}$ for $1 \mathrm{~min}$ followed by a $30^{\circ} \mathrm{C} / \mathrm{min}$ ramp to a final temperature of $300{ }^{\circ} \mathrm{C}$ which was maintained for $3 \mathrm{~min}$. A $3.2 \mathrm{~min}$ solvent delay was used. The MSD was set to scan the 40-1050 m/z range. Data collection and analysis were performed using MSD Enhanced Chemstation software (G1701EA, Agilent, Wilmington, DE, USA). Product spectra were identified by comparison of the measured fragmentation patterns to those found in the NIST 08 Mass Spectral Library.

\subsection{Liquid Chromatography-Mass Spectrometry (LC-MS)}

For LC-MS quantification of lawsone, prepared liposomes were dissolved in methanol and $10 \mu \mathrm{L}$ was injected in to LC-MS. LC-MS analyses were carried out in negative ion mode by electrospray ionization (ESI) on a ACQUITY UPLC triple quadrupole (Xevo TQD, Waters, Milford, MA, USA) instrument equipped with MassLynx software (4.1, Waters, Milford, MA, USA ). The solvent system was (A: $100 \%$ acetonitrile and B: water containing $0.1 \%$ formic acid). The solvent gradient was 0-10 $\mathrm{min} / 75 \% \mathrm{~A}, 8 \mathrm{~min} / 100 \% \mathrm{~A}, 2 \mathrm{~min} / 75 \% \mathrm{~A}$ and $3 \mathrm{~min} / 75 \%$ A. The flow rate was $0.3 \mathrm{~mL} / \mathrm{min}$ and the injection volume was $10 \mu \mathrm{L}$. All solvents and reagents were HPLC grade and used without further purification.

\subsection{Liposome Preparation and Drug Loading Using Solvent Dispersion Ether Injection (Solvent Vaporization) Method}

Phospholipids $(100 \mathrm{mg} / \mathrm{mL})$ and essential oil $(80 \mu \mathrm{g} / \mathrm{mL})$ isolated from Calligonum were dissolved in diethyl ether and then vortexed for $5 \mathrm{~min}$. The solution was then gradually injected to an aqueous solution of lawsone $(100 \mu \mathrm{g} / \mathrm{mL})$ at $55^{\circ} \mathrm{C}$. The ether was then removed under vacuum $[37,38]$ and the solution left was centrifuged at $10,000 \times g$ for $15 \mathrm{~min}$, followed by aspiration of water and vacuum dried.

\subsection{Statistical Analysis}

The data was collected and graphed using Microsoft Excel and Graph Pad (5.04, La Jolla, CA, USA) for Windows for statistical analysis. The effects of individual natural substance or in combination on MDR bacteria and Candida spp. inoculated onto solid agar media and liquid broth was analyzed by one-way analysis of variance (ANOVA) using Dunnett's Multiple Comparison Test. A p-value $<0.05$ was considered as significant.

Supplementary Materials: Tables indicating the MIC of all tested substances are available online.

Acknowledgments: This work was supported by grants from University of Sharjah, UAE (1601110215-P) to S.S.M.S. and by a Public Health Service grant R01 AI063503 to A.S.I.

Author Contributions: S.S.M.S. and A.I.A. designed and performed the experiments; E.G.Y. helped on performing anti-Candida and toxicity assays; G.K. helped on the GC-MS analysis; A.M.N. contributed reagents/materials/analysis; S.S.M.S., M.I.H. and A.S.I. analyzed the data and wrote the paper.

Conflicts of Interest: The authors declare no conflict of interest.

\section{References}

1. Patra, A.K. An overview of antimicrobial properties of different classes of phytochemicals. In Dietary Phytochemicals and Microbes; Springer: New York, NY, USA, 2012; pp. 1-32.

2. Nasiri, H.R.; Madej, M.G.; Panisch, R.; Lafontaine, M.; Bats, J.W.; Lancaster, C.R.D.; Schwalbe, H. Design, synthesis, and biological testing of novel naphthoquinones as substrate-based inhibitors of the quinol/fumarate reductase from Wolinella succinogenes. J. Med. Chem. 2013, 56, 9530-9541. [CrossRef] [PubMed]

3. Sritrairat, N.; Nukul, N.; Inthasame, P.; Sansuk, A.; Prasirt, J.; Leewatthanakorn, T.; Piamsawad, U.; Dejrudee, A.; Panichayupakaranant, P.; Pangsomboon, K. Antifungal activity of lawsone methyl ether in comparison with chlorhexidine. J. Oral Pathol. Med. 2011, 40, 90-96. [CrossRef] [PubMed] 
4. Rahmoun, N.M.; Boucherit-Otmani, Z.; Boucherit, K.; Benabdallah, M.; Villemin, D.; Choukchou-Braham, N. Antibacterial and antifungal activity of lawsone and novel naphthoquinone derivatives. Med. Mal. Infect. 2012, 42, 270-275. [CrossRef] [PubMed]

5. Saeed, S.M.G.; Sayeed, S.A.; Ashraf, S.; Naz, S.; Siddiqi, R.; Ali, R.; Mesaik, M.A. A new method for the isolation and purification of lawsone from Lawsonia inermis and its ROS inhibitory activity. Pak. J. Bot. 2013, 45, 1431-1436.

6. El-Shaer, N.S.; Badr, J.M.; Aboul-Ela, M.A.; Gohar, Y.M. Determination of lawsone in henna powders by high performance thin layer chromatography. J. Sep. Sci. 2007, 30, 3311-3315. [CrossRef] [PubMed]

7. Sakunphueak, A.; Panichayupakaranant, P. Comparison of antimicrobial activities of naphthoquinones from Impatiens balsamina. Nat. Prod. Res. 2012, 26, 1119-1124. [CrossRef] [PubMed]

8. Patel, M.M.; Solanki, B.R.; Gurav, N.C.; Patel, P.H.; Verma, S.S. Method development for lawsone estimation in Trichup herbal hair powder by high-performance thin layer chromatography. J. Adv. Pharm. Technol. Res. 2013, 4, 160-165. [PubMed]

9. Burt, S. Essential oils: Their antibacterial properties and potential applications in foods-A review. Int. J. Food. Microbiol. 2004, 94, 223-253. [CrossRef] [PubMed]

10. Hurdle, J.G.; O’Neill, A.J.; Chopra, I.; Lee, R.E. Targeting bacterial membrane function: An underexploited mechanism for treating persistent infections. Nat. Rev. Microbiol. 2011, 9, 62-75. [CrossRef] [PubMed]

11. Burt, S.A.; Reinders, R.D. Antibacterial activity of selected plant essential oils against Escherichia coli O157:H7. Lett. Appl. Microbiol. 2003, 36, 162-167. [CrossRef] [PubMed]

12. Langeveld, W.T.; Veldhuizen, E.J.A.; Burt, S.A. Synergy between essential oil components and antibiotics: A review. Crit. Rev. Microbiol. 2014, 40, 76-94. [CrossRef] [PubMed]

13. Sikkema, J.; de Bont, J.A.; Poolman, B. Mechanisms of membrane toxicity of hydrocarbons. Microbiol. Rev. 1995, 59, 201-222. [PubMed]

14. Zouari, S.; Dhief, A.; Aschi-Smiti, S. Chemical composition of essential oils of Calligonum comosum cultivated at the south-eastern of Tunisia: A comparative study between flowering and fructification stages. J. Essent. Oil Bear. Plants 2012, 15, 320-327. [CrossRef]

15. Riadh, H.; Imen, F.; Abdelmajid, Z.; Sinda, F. Detection and extraction of anti-listerial compounds from Calligonum comosum, a medicinal plant from arid regions of Tunisia. Afr. J. Tradit. Complement. Altern. Med. 2011, 8, 322-327.

16. Ebid, A.I. Anti-bacterial activity of folk medicinal plant extracts of Saudi Arabia on isolated bacteria. J. Appl. Life Sci. Int. 2015, 3, 49-54. [CrossRef]

17. Chouikh, A.; Mekki, M.; Adjal, E. Effects of extraction methods on antibacterial activity of different extracts of Calligonum comosum L'Her. Growing in Sahara Algerian. Int. J. Recent Sci. Res. 2015, 6, 3534-3536.

18. Aflatuni, A. The Yield and Essential Oil Content of Mint (Mentha ssp.) in Northern Ostrobothnia; Oulu University Press: Oulu, Finland, 2005.

19. Ullah, I.; Khan, A.L.; Ali, L.; Khan, A.R.; Waqas, M.; Hussain, J.; Lee, I.-J.; Shin, J.-H. Benzaldehyde as an insecticidal, antimicrobial, and antioxidant compound produced by Photorhabdus temperata M1021. J. Microbiol. 2015, 53, 127-133. [CrossRef] [PubMed]

20. Naveed, R.; Hussain, I.; Tawab, A.; Tariq, M.; Rahman, M.; Hameed, S.; Mahmood, M.S.; Siddique, A.B.; Iqbal, M. Antimicrobial activity of the bioactive components of essential oils from Pakistani spices against Salmonella and other multi-drug resistant bacteria. BMC Complement. Altern. Med. 2013, 13, 265. [CrossRef] [PubMed]

21. Gómez, B.; Nosanchuk, J. Melanin and fungi. Curr. Opin. Infect. Dis. 2003, 16, 91-96. [CrossRef] [PubMed]

22. Yap, P.S.X.; Yiap, B.C.; Ping, H.C.; Lim, S.H.E. Essential oils, a new horizon in combating bacterial antibiotic resistance. Open Microbiol. J. 2014, 8, 6-14. [CrossRef] [PubMed]

23. Gibbons, S.; Oluwatuyi, M.; Veitch, N.C.; Gray, A.I. Bacterial resistance modifying agents from Lycopus europaeus. Phytochemistry 2003, 62, 83-87. [CrossRef]

24. Jones, M.N. The surface properties of phospholipid liposome systems and their characterisation. Adv. Colloid Interface Sci. 1995, 54, 93-128. [CrossRef]

25. Vemuri, S.; Rhodes, C. Preparation and characterization of liposomes as therapeutic delivery systems: A review. Pharm. Acta Helv. 1995, 70, 95-111. [CrossRef]

26. Schiffelers, R.; Storm, G.; Bakker-Woudenberg, I. Liposome-encapsulated aminoglycosides in pre-clinical and clinical studies. J. Antimicrob. Chemother. 2001, 48, 333-344. [CrossRef] [PubMed] 
27. Bakker-Woudenberg, I.A.J.M.; Lokerse, A.F.; ten Kate, M.T.; Melissen, P.M.B.; van Vianen, W.; van Etten, E.W.M. Liposomes as carriers of antimicrobial agents or immunomodulatory agents in the treatment of infections. Eur. J. Clin. Microbiol. Infect. Dis. 1993, 12, S61-S67. [CrossRef] [PubMed]

28. Sherry, M.; Charcosset, C.; Fessi, H.; Greige-Gerges, H. Essential oils encapsulated in liposomes: A review. J. Liposome Res. 2013, 23, 268-275. [CrossRef] [PubMed]

29. Wasan, K.M.; Morton, R.E.; Rosenblum, M.G.; Lopez-Berestein, G. Decreased toxicity of liposomal amphotericin B due to association of amphotericin B with high density lipoproteins. J. Pharm. Sci. 1994, 83, 1006-1010. [CrossRef] [PubMed]

30. Kokoska, L.; Havlik, J.; Valterova, I.; Sovova, H.; Sajfrtova, M.; Jankovska, I. Comparison of chemical composition and antibacterial activity of Nigella sativa seed essential oils obtained by different extraction methods. J. Food Prot. 2008, 71, 2475-2480. [CrossRef] [PubMed]

31. Kirkpatrick, W.R.; McAtee, R.K.; Revankar, S.G.; Fothergill, A.W.; McCarthy, D.I.; Rinaldi, M.G.; Patterson, T.F. Comparative evaluation of national committee for clinical laboratory standards broth macrodilution and agar dilution screening methods for testing fluconazole susceptibility of Cryptococcus neoformans. J. Clin. Microbiol. 1998, 36, 1330-1332. [PubMed]

32. Hasselmann, C. Determination of minimum inhibitory concentrations (MICs) of antibacterial agents by broth dilution. Clin. Microbiol. Infect. 2003, 9, ix-xv.

33. Subcommittee of Antifungal Susceptibility Testing of the ESCMID European Committee for Antimicrobial Susceptibility Testing. EUCAST Technical Note on the method for the determination of broth dilution minimum inhibitory concentrations of antifungal agents for conidia-forming moulds. Clin. Microbiol. Infect. 2008, 14, 982-984.

34. Bokori-Brown, M.; Martin, T.G.; Naylor, C.E.; Basak, A.K.; Titball, R.W.; Savva, C.G. Cryo-EM structure of lysenin pore elucidates membrane insertion by an aerolysin family protein. Nat. Commun. 2016, 7, 11293. [CrossRef] [PubMed]

35. Stark, M.; Liu, L.-P.; Deber, C.M. Cationic hydrophobic peptides with antimicrobial activity. Antimicrob. Agents Chemother. 2002, 46, 3585-3590. [CrossRef] [PubMed]

36. Ibrahim, A.S.; Gebremariam, T.; Liu, M.; Chamilos, G.; Kontoyiannis, D.P.; Mink, R.; Kwon-Chung, K.J.; Fu, Y.; Skory, C.D.; Edwards, J.E.; et al. Bacterial endosymbiosis is widely present among Zygomycetes but does not contribute to the pathogenesis of Mucormycosis. J. Infect. Dis. 2008, 198, 1083-1090. [CrossRef] [PubMed]

37. Deamer, D.; Bangham, A.D. Large volume liposomes by an ether vaporization method. BBA Biomembr. 1976, 443, 629-634. [CrossRef]

38. Schieren, H.; Rudolph, S.; Finkelstein, M.; Coleman, P.; Weissmann, G. Comparison of large unilamellar vesicles prepared by a petroleum ether vaporization method with multilamellar vesicles. BBA Gen. Subj. 1978, 542, 137-153. [CrossRef]

Sample Availability: Samples of the compounds are not available.

(C) 2017 by the authors. Licensee MDPI, Basel, Switzerland. This article is an open access article distributed under the terms and conditions of the Creative Commons Attribution (CC BY) license (http:/ / creativecommons.org/licenses/by/4.0/). 